\title{
Reasons for Extraction of Permanent Teeth in General Dental Practices in Tehran, Iran
}

\author{
M. Jafarian ${ }^{a, b} \quad$ A. Etebarian ${ }^{a}$ \\ a Dental Research Center, Research Institute of Dental Sciences of Shahid Beheshti University of Medical Sciences, and \\ ${ }^{b}$ Department of Oral and Maxillofacial Surgery, Dental School, Shahid Beheshti University of Medical Sciences, \\ Tehran, Iran
}

\section{Key Words}

Tooth extraction $\cdot$ Dental caries $\cdot$ Periodontal disease

\begin{abstract}
Objectives: The aim of this survey was to investigate the primary reason for extraction of permanent teeth, its correlations with age, gender and education level, as well as identify the important predictors for dental caries in general dental centers in Tehran, Iran. Subjects and Methods: The study was conducted over a period of 6 months; its population consisted of 1,382 patients, aged 9-95 years, who underwent tooth extraction. There were $673(47.8 \%)$ male and 709 (51.3\%) female patients. The frequency distribution was calculated using the $\chi^{2}$ test, ANOVA and $t$ test for differences in mean number of extracted teeth and the logistic regression model to evaluate the variables associated with reasons for tooth extraction. Results: A total of 2,620 teeth were extracted from the 1,382 patients. The highest rate $(36.9 \%)$ of extraction occurred for those 41-60 years old. Males comprised $48.7 \%$ of patients but had more teeth $(1,470,55.3 \%)$ extracted than females $(1,150,43.9 \%)$. Nine hundred and thirty-six (67.7\%) patients had incomplete secondary education or less. Tooth loss due to caries was 51\%; periodontal disease was $14.4 \%$; supernumerary and tooth impaction $13.9 \%$.
\end{abstract}

\section{KARGER}

E-Mail karger@karger.com www.karger.com/mpp

\section{(c) 2012 S. Karger AG, Basel} 1011-7571/13/0223-0239\$38.00/0

Karger Open access

This is an Open Access article licensed under the terms of the Creative Commons Attribution- NonCommercial-NoDerivs 3.0 License (www.karger.com/OA-license), applicable to the online version of the article only. Distribution for non-commercial purposes only.
There was a significant association between patient characteristics (age, gender and education level) and number of teeth extracted. Conclusion: Dental caries and periodontal disease were the main reasons for tooth extraction in Tehran, Iran.

Copyright $\odot 2012$ S. Karger AG, Basel

\section{Introduction}

Tooth extraction is one of the dental treatments which should be considered the last option. A decrease in the number of teeth may result in poor dietary habit and deterioration of quality of life [1]. The number of extracted teeth can serve as an indicator of socio-economic and oral hygiene level [2]. Extraction of permanent teeth is performed for several reasons including dental caries, periodontal disease, orthodontic reasons, impacted teeth, failed dental treatment, prosthetic indications and other reasons.

An understanding of the reasons why teeth are extracted is essential to improve oral health outcomes. A large number of cross-sectional studies have investigated for tooth loss in different countries. Dental caries was the main cause for tooth loss [3-9], but a few studies revealed 
Table 1. Mean number of teeth extracted according to patients' gender, age and education level

\begin{tabular}{|c|c|c|c|}
\hline & $\begin{array}{l}\text { Previous } \\
\text { extraction }\end{array}$ & $\begin{array}{l}\text { Extraction } \\
\text { on the day } \\
\text { of survey }\end{array}$ & Total \\
\hline \multicolumn{4}{|l|}{ Gender ${ }^{a}$} \\
\hline Male $(n=673)$ & $5.1 \pm 0.3$ & $2.2 \pm 0.1$ & $7.3 \pm 0.3$ \\
\hline Female $(\mathrm{n}=709)$ & $3.8 \pm 0.2$ & $1.6 \pm 0.04$ & $5.4 \pm 0.2$ \\
\hline \multicolumn{4}{|l|}{ Age group in years ${ }^{b}$} \\
\hline$\leq 20(\mathrm{n}=142)$ & $0.5 \pm 0.1$ & $1.6 \pm 0.1$ & $2.1 \pm 0.1$ \\
\hline $21-30(\mathrm{n}=443)$ & $1.2 \pm 0.1$ & $1.7 \pm 0.1$ & $2.9 \pm 0.1$ \\
\hline $31-40(\mathrm{n}=245)$ & $3.3 \pm 0.3$ & $1.5 \pm 0.1$ & $4.8 \pm 0.3$ \\
\hline $41-50(n=242)$ & $6.2 \pm 0.4$ & $2.3 \pm 0.1$ & $8.5 \pm 0.4$ \\
\hline $51-60(n=176)$ & $8.1 \pm 0.5$ & $2.3 \pm 0.2$ & $10.4 \pm 0.6$ \\
\hline $61-70(\mathrm{n}=85)$ & $11.2 \pm 0.9$ & $2.3 \pm 0.2$ & $13.5 \pm 1.0$ \\
\hline$\leq 71(\mathrm{n}=49)$ & $16.1 \pm 1.4$ & $2.1 \pm 0.2$ & $18.2 \pm 1.5$ \\
\hline \multicolumn{4}{|l|}{ Education level $^{b}$} \\
\hline \multicolumn{4}{|l|}{ Complete secondary school } \\
\hline \multicolumn{4}{|c|}{ Incomplete secondary school } \\
\hline$(\mathrm{n}=772)$ & $4.4 \pm 0.2$ & $1.8 \pm 0.1$ & $6.2 \pm 0.2$ \\
\hline $\begin{array}{l}\text { Primary school and lower } \\
\qquad(\mathrm{n}=164)\end{array}$ & $9.5 \pm 0.7$ & $2.4 \pm 0.1$ & $11.9 \pm 0.7$ \\
\hline Total $(\mathrm{n}=1,382)$ & $4.4 \pm 0.2$ & $1.9 \pm 0.5$ & $6.3 \pm 0.2$ \\
\hline
\end{tabular}

${ }^{\mathrm{a}}$ t test: $\mathrm{p}<0.001 .{ }^{\mathrm{b}}$ ANOVA: $\mathrm{p}<0.001$.

that a greater proportion of tooth extractions were due to periodontal disease [10-12]. Not enough data are available in Iran and information on this topic is strongly needed. By identifying the main causes and predictors for tooth loss, it may be possible to limit future extractions and highlight the crucial role of prevention. Therefore, the purpose of this paper was to investigate the reasons for extraction of permanent teeth, its correlations to several aspects such as age, gender and educational level and the best predictors for dental caries in Tehran.

\section{Materials and Methods}

This cross-sectional, multicenter study of consecutive sampling was focused on general dental centers in a population of Iran. In the Tehran health service system, patients seek dental care mostly from public, but also from private practices. There are 5 health districts based on the residential area in Iran. A representative sample of the 3 Tehran health districts was randomly selected. Dentists who agreed to take part in the study were interviewed by the authors to explain the objects of the survey. Moreover, a list of definitions for possible reasons for tooth extraction was discussed with general practitioners so that their replies would be as specific as possible. The questionnaire was divided into two parts. They first asked for the patient's gender, age, marital status, education level, history of smoking and the time of last dental visit. This part could be completed by the receptionist or dental assistant. The second half was completed by dentists and documented the information on previous dental extractions, tooth type and the reason for each extraction that was to be performed on the day of survey. Dentists were asked to record the code of tooth type and the main reason for each extraction. All permanent teeth extracted, including third molars, during the 6-month study period (December 2010 to May 2011) were recorded.

An informed consent form was obtained from all patients. The design of the record form was tested and modified in a 1-month pilot study before the data selection. Every month, the completed questionnaires were collected from each center.

The reasons for extraction were analyzed for each tooth type in the upper and lower arch. Data were not divided into right and left quadrants as the previous surveys have shown no differences in the rates of extraction for right and left sides of the oral cavity $[1,13]$.

The data were entered and analyzed using the SPSS software (version 16.0). The relationships of the categorical background variables, such as age range, gender and education level, with reasons for tooth extraction were analyzed by the $\chi^{2}$ test, while differences in the mean number of extracted teeth per patient were analyzed with ANOVA and t test methods. A logistic regression model was used to evaluate the variables associated with reasons for tooth loss, considering tooth extraction due to caries and other causes such as periodontal disease, impaction and malocclusion. Multivariate analyses were used to identify predictors of reasons for tooth extraction. The significant variables in the bivariate analyses were included in a model of logistic regression based on the Wald $\chi^{2}$ statistic. A p value of less than 0.5 was considered to be statistically significant.

\section{Results}

Males comprised $48.7 \%$ of patients but they had more teeth extracted $(56.1 \%)$ than females $(\mathrm{p}<0.05)$. According to table 1 , the average number of teeth extracted per patient on the day of survey was $1.9 \pm 0.5$ (2.2 in males and 1.6 in females). In total, patients older than 71 years of age lost 18.2 teeth, more than all other age groups, as measured by the mean number of teeth lost per patient $(\mathrm{p}<0.05)$. The highest rates of extraction on the day of survey were in patients from 41 to 70 years old ( 2.3 teeth). Moreover, patients with the lowest level of education had lost 11.9 teeth in total, being significantly higher than in other groups $(\mathrm{p}<0.05)$.

Dental caries was responsible for $51 \%$ of all extractions, while periodontal reasons accounted for $14.4 \%$. Impacted or supernumerary teeth (13.9\%) and orthodontic 
Table 2. Reasons for tooth extraction by age, gender and education level

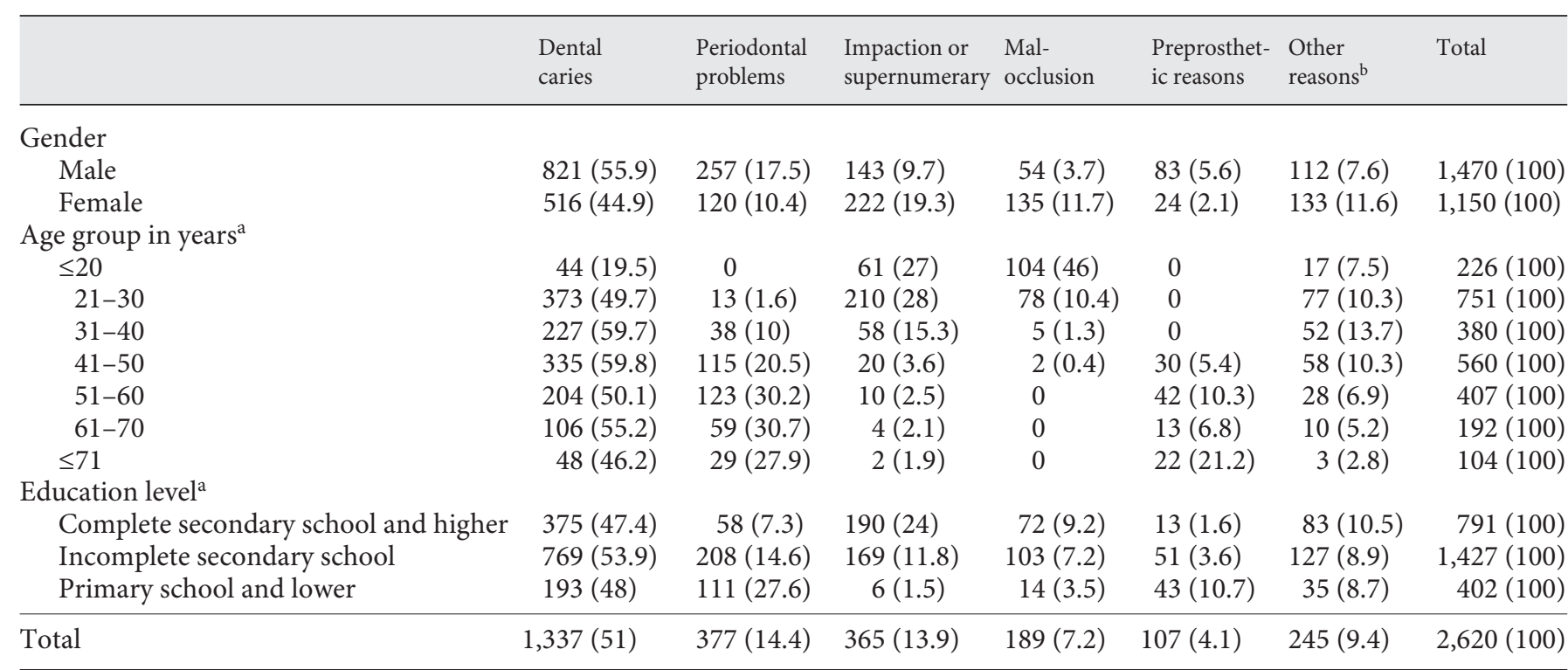

Figures are numbers with percentages in parentheses.

${ }^{\mathrm{a}} \chi^{2}$ test: $\mathrm{p}<0.001$.

b Other reasons include: failure of previous dental treatment, financial problems, trauma esthetic reasons and others.

Table 3. Reasons for extraction by tooth type, $\mathrm{n}(\%)$

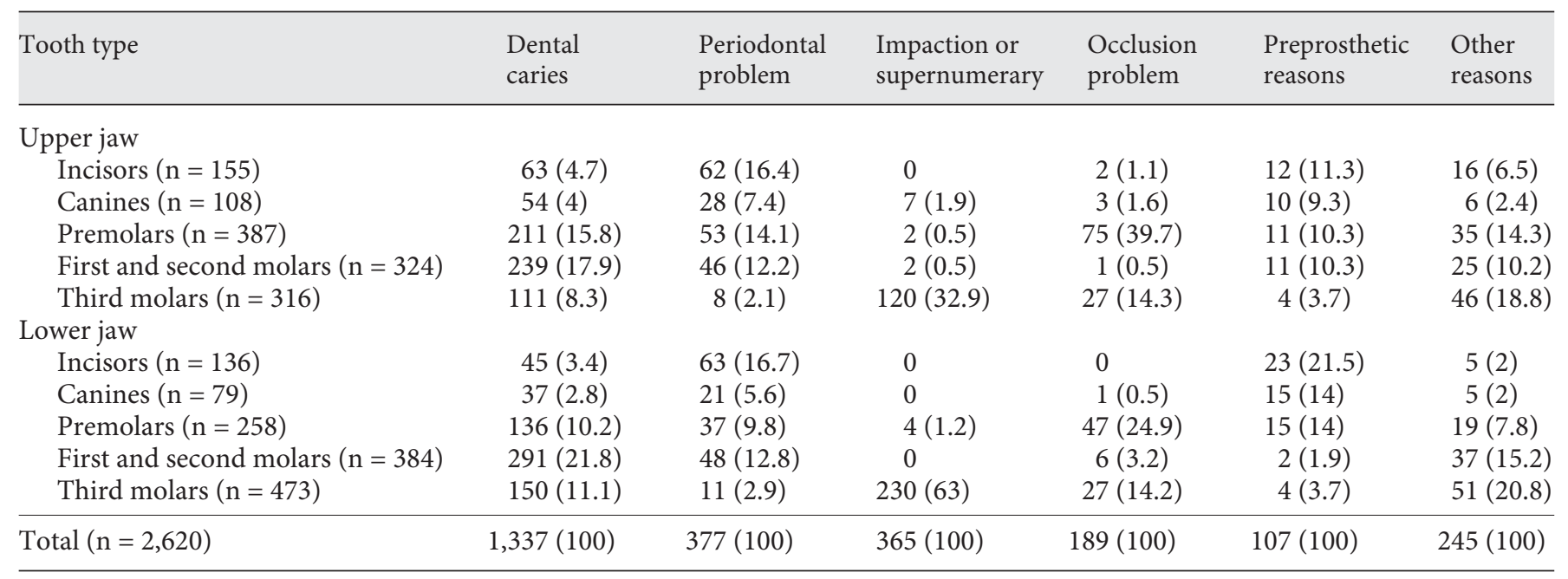

reasons (7.2\%) were the next most common reasons for tooth loss (table 2). Although dental caries was responsible for most extractions in both genders, caries and periodontal disease were more common in males than females. Moreover, impaction and malocclusion were the main causes for tooth extraction among females. While caries was the leading cause for tooth extraction among patients above 20 years of age, impaction and malocclusions were the common reasons for tooth loss in patients under 20. On the other hand, periodontal disease was the second most common reason for tooth loss in patients above 40 years of age. Patients having incomplete second- 
Table 4. Logistic regression for tooth extraction due to caries

\begin{tabular}{|c|c|c|c|}
\hline Variable selected & $\begin{array}{l}\text { Beta value } \\
\text { (standard error) }\end{array}$ & $\begin{array}{l}\text { Odds ratio } \\
(95 \% \mathrm{CI})\end{array}$ & $\mathrm{p}$ value \\
\hline \multicolumn{4}{|l|}{ Age group (ref: $\leq 20)$} \\
\hline $41-60$ years & $0.7(0.2)$ & $2.1(1.3-3.2)$ & $0.001^{*}$ \\
\hline$\leq 61$ years & $0.6(0.2)$ & $1.8(1.1-2.9)$ & $0.01^{*}$ \\
\hline \multicolumn{4}{|l|}{ Gender (ref: male) } \\
\hline Married & $0.3(0.1)$ & $1.4(1.1-1.8)$ & $0.002 *$ \\
\hline \multicolumn{4}{|c|}{ Education level (ref: complete secondary school and higher) } \\
\hline Incomplete secondary school & $0.1(0.1)$ & $1.1(0.8-1.3)$ & 0.51 \\
\hline Primary school and lower & $-0.3(0.1)$ & $0.7(0.5-0.9)$ & $0.01^{*}$ \\
\hline \multicolumn{4}{|l|}{ Smoking (ref: no) } \\
\hline \multicolumn{4}{|c|}{ Time of last dental visit (ref: less than 6 months) } \\
\hline Never before & $0.5(0.3)$ & $1.6(0.9-2.8)$ & 0.097 \\
\hline \multicolumn{4}{|l|}{ Tooth type (ref: incisors and canines) } \\
\hline 1 st, 2 nd premolars and molars & $1(0.1)$ & $2.9(2.3-3.5)$ & $0.0001^{*}$ \\
\hline 3rd molars & $0.4(0.1)$ & $1.5(1.2-1.9)$ & $0.0001^{*}$ \\
\hline \multicolumn{4}{|l|}{ Having a previous extraction (ref: no) } \\
\hline Yes & $0.4(0.1)$ & $1.5(1.2-1.8)$ & $0.0001^{*}$ \\
\hline
\end{tabular}

The asterisk indicates the significance of parameter sets at $5.0 \%$.

ary school education or lower had lost more teeth due to caries and periodontal disease compared with patients having higher education levels $(\mathrm{p}<0.001)$.

The most frequently extracted teeth were lower third molars $(473,18 \%)$, followed by upper premolars (387, $14.77 \%)$, while lower canines were least frequently extracted $(79,3 \%)$. Impaction was the main cause for loss of upper and lower third molars (table 3). Premolars, first and second molars of both jaws were the most frequently extracted teeth due to dental caries. Additionally, periodontal disease was the main cause for the loss of all incisors $(\mathrm{p}<0.001)$.

The final logistic regression model that identified the variables associated with tooth loss due to caries is shown in table 4. Age, gender, marital status, time of last dental visit, tooth type and having had a previous extraction were significantly associated with tooth extraction due to caries $(\mathrm{p}<0.05)$. However, education level and smoking habits were not significantly associated with tooth loss $(\mathrm{p}<0.05)$.

\section{Discussion}

The results of this survey indicated that in Tehran, Iran, dental caries and its complications were the leading reason for extraction. Periodontal disease was the next most common reason. The finding that caries was the most common reason is in agreement with the majority of similar studies [3-9]. Surveys in Japan [1], Italy [14] and Singapore [15] showed that both caries and periodontal disease were almost equally important reasons for tooth loss. Studies in Canada [11, 12] and Jordan [10] showed that the main cause of tooth loss was periodontal disease. Germany [16] and Singapore [15] had a lower percentage of dental caries compared to our study and many earlier studies $[3,5,17,18]$. This difference may be attributed to diet, socio-economic factors, level of dental awareness as well as water fluoridation in these countries $[15,16]$.

In this study, most patients whose teeth were extracted were 20-50 years old, while extraction in elderly patients (over 60 ) accounted for only $9.7 \%$ of all tooth loss. Although $86 \%$ of teeth extracted for periodontal disease were in patients over 40 years of age, caries was still the 
main reason for extraction even in elderly patients, but to a less degree than in younger ones. This result was also reported by Thomas and Al-Maqdassy [19]. However, our study, as previously mentioned, is not in agreement with studies where periodontal disease was the major cause of extraction in patients over 40 years old $[2,4,12,14,15]$. It may be that extractions caused by caries are happening later in the disease process, perhaps following initial attempts to treat the tooth. In other words, if more teeth are restored rather than extracted, then extractions would be deferred to an older age group. Thus, the continuing high frequency of extraction for caries may reflect an increase in restorations prior to extraction rather than high incidence of caries in older people.

In this survey, the mean number of teeth extracted per patient was 1.9, higher than the 1.26 reported by Angelilli et al. [14] in Italy and the 1.3 found by Corbet and Davies [7] in Hong Kong, but lower than the 2.42 reported by Chrysanthakopoulos [2] in a recent study in Greece and the 2.3 found by Murray et al. [12] in Canada. These variations are at least partly attributed to methodological differences, different response rates as well as the age of the population sample. Thus, comparison of tooth extraction data between different countries is fraught with difficulty.

When considering all the teeth patients had extracted until the day of examination, the mean number of tooth loss in patients over 70 was 18.22 , the highest among all age groups. This finding confirmed the evidence for increasing prevalence of tooth loss with increasing age [14, 20]. Third molars were the most frequently extracted teeth $[19,20]$, mainly for impaction reasons $[3,5,14]$, while first and second molars were mainly extracted due to dental caries $[3,14,16,18]$.

Periodontal disease was the principal cause of the tooth loss in incisors $[7,14,18]$ and teeth extracted for orthodontic reasons were mainly first and second premolars $[3,14]$. A likely reason for the high periodontal extraction in anterior teeth is that they are less susceptible to caries, retained longer in the mouth, and then may be subjected to the risk of periodontal disease $[2,4,15,17]$.

Orthodontic reasons, not surprisingly, were predominant in patients under 20 years of age $[3,14,16,18]$. No one under 20 had extractions due to periodontal disease $[3,14,16]$.

Females under 50 years of age, who accounted for $51.3 \%$ of all patients, lost more teeth $(79.6 \%)$ compared to males $(68 \%)$ who had better retention of their teeth during these years. Multiple tooth loss, however, was higher in men due to their lack of interest in spending more time on complicated restorative treatments rather than extractions. This finding also confirmed the results in Afghanistan [8].

There was proportionally more extraction for caries in men than in women, a finding which is in agreement with other studies $[9,13,17,21]$. While caries and impaction were the main causes of tooth loss in females, males lost more teeth due to caries and periodontal disease. The second finding was also similar to previous investigations [2, $4,22,23]$. Moreover, male gender has been reported as a risk indicator for periodontal disease severity $[2,4,24]$.

Subjects with higher education levels had fewer tooth extractions than those with incomplete or lower education levels. This relationship is in agreement with other studies in which tooth loss was associated with a low level of education [9, 21, 25-28].

Studies on tooth loss have generally discussed very few factors associated with missing teeth $[9,28,29]$. In this study, several predictors for tooth loss due to caries were considered. Patients' age had a significant association with dental caries, while a study by Jovino-Silveria et al. in Brazil [9] showed age as the best predictor for tooth loss due to periodontal disease. Although patients' education level had influenced reasons for tooth loss, it was not a predictor for extraction due to caries. This result did not support the findings in Brazil either [9]. These differences could be attributed to variations in study designs, caries prevalence in the population, cultural background, availability of dental services, overrepresentation of a certain age range and attitudes toward the retention of teeth by both patients and dental professionals.

Despite the fluoride-related preventive efforts in primary schools as a national protocol since 1997 [26, 27, 30], dental caries remains the major problem in a proportion of the population. Regular dental checkups are still not a routine pattern of behavior for all. Diagnosing caries at an early stage before its progression can prevent extensive dental treatment and the least wanted result of tooth extraction. Furthermore, strategies for efficient ways of screening for periodontal disease, especially for middleaged people, might be required.

Future studies could be focused on changes in reasons for dental extraction in a time trend to determine whether or not their relative importance has changed. Intervention studies could also be carried out with the available data and more surveys could be conducted to compare extraction patterns between public and private dental practices. 


\section{Conclusion}

The results of this survey indicated that caries and periodontal disease were the principal reasons for tooth extraction in Tehran, Iran. The majority of patients had incomplete secondary education or lower and had even more teeth extracted than patients having higher levels of education. The best predictors for tooth loss due to caries were age, gender, marital status, time of last dental visit, tooth type and having had a previous extraction.

\section{Acknowledgements}

We extend our sincere thanks to all dentists and patients who kindly agreed to take part in this study, Dr. Fatemeh Mohammadi and Marjan Khalafi for their technical support as well as the Dental Research Center, Research Institute of Dental Sciences of Shahid Beheshti University of Medical Sciences for providing the funding.

\section{References}

1 Aida J, Ando Y, Akhter R, Aoyama H, Masui M, Morita M: Reasons for permanent tooth extractions in Japan. J Epidemiol 2006;16: 214-219.

2 Chrysanthakopoulos NA: Reasons for extraction of permanent teeth in Greece: a fiveyear follow-up study. Int Dent J 2011;61:1924.

3 Agerholm DM, Sidi AD: Reasons given for extraction of permanent teeth by general dental practitioners in England and Wales. Br Dent J 1988;164:345-348.

4 Al-Shammari KF, Al-Ansari JM, Al-Melh MA, Al-Khabbaz AK: Reasons for tooth extraction in Kuwait. Med Princ Pract 2006; 15: 417-422.

5 Chen SC, Chueh LH, Hsiao CK, Wu HP, Chiang $\mathrm{CP}$ : First untoward events and reasons for tooth extraction after nonsurgical endodontic treatment in Taiwan. J Endod 2008; 34:671-674.

6 Chestnutt IG, Binnie VI, Taylor MM: Reasons for tooth extraction in Scotland. J Dent 2000;28:295-297.

7 Corbet EF, Davies WI: Reasons given for tooth extraction in Hong Kong. Community Dent Health 1991;8:121-130.

8 Da'ameh D: Reasons for permanent tooth extraction in the North of Afghanistan. J Dent 2006;34:48-51.

-9 Jovino-Silveira RC, Caldas AF Jr, de Souza EH, Gusmão ES: Primary reason for tooth extraction in a Brazilian adult population. Oral Health Prev Dent 2005;3:151-157.

-10 Haddad I, Haddadin K, Jebrin S, Ma’Ani M, Yassin O: Reasons for extraction of permanent teeth in Jordan. Int Dent J 1999;49:343346.
11 Matthews DC, Smith CG, Hanscom SL: Tooth loss in periodontal patients. J Can Dent Assoc 2001;67:207-210.

12 Murray H, Locker D, Kay EJ: Patterns of and reasons for tooth extractions in general dental practice in Ontario, Canada. Community Dent Oral Epidemiol 1996;24:196-200.

13 McCaul LK, Jenkins WMM, Kay EJ: The reasons for the extraction of various tooth types in Scotland: a 15 -year follow up. J Dent 2001; 29:401-407.

14 Angelillo IF, Nobile CGA, Pavia M: Survey of reasons for extraction of permanent teeth in Italy. Community Dent Oral Epidemiol 1996;24:336-340.

15 Ong G, Yeo JF, Bhole S: A survey of reasons for extraction of permanent teeth in Singapore. Community Dent Oral Epidemiol 1996;24:124-127.

16 Reich E, Hiller KA: Reasons for tooth extraction in the western states of Germany. Community Dent Oral Epidemiol 1993;21:379383.

17 Kay EJ, Blinkhorn AS: The reasons underlying the extraction of teeth in Scotland. $\mathrm{Br}$ Dent J 1986;160:287-290.

18 Morita M, Kimura T, Kanegae M, Ishikawa A, Watanabe T: Reasons for extraction of permanent teeth in Japan. Community Dent Oral Epidemiol 1994;22:303-306.

19 Thomas S, Al-Maqdassy SE: Causes and pattern of tooth mortality among adult patients in a teaching dental hospital. Ibnosina J Med BS 2010;2:160-167.

20 Marcus SE, Kaste LM, Brown LJ: Prevalence and demographic correlates of tooth loss among the elderly in the United States. Spec Care Dentist 1994;14:123-127.

21 Caldas AF Jr, Marcenes W, Sheiham A: Reasons for tooth extraction in a Brazilian population. Int Dent J 2000;50:267-273.
22 Fardal Ø, Johannessen AC, Linden GJ: Tooth loss during maintenance following periodontal treatment in a periodontal practice in Norway. J Clin Periodontol 2004;31:550555.

23 Locker D, Ford J, Leake J: Incidence of and risk factors for tooth loss in a population of older Canadians. J Dent Res 1996;75:783789.

24 Grossi S, Genco R, Machtei E, Ho A, Koch G, Dunford R, Zambor JJ, Hausmann E: Assessment of risk for periodontal disease. 2. Risk indicators for alveolar bone loss. J Periodontol 1995;66:23-29.

25 Hamasha AAH, Al Qudah MA, Bataineh $A B$, Safadi RA: Reasons for third molar teeth extraction in Jordanian adults. J Contemp Dent Pract 2006;7:88-95.

26 Hessari H, Vehkalahti MM, Eghbal MJ, Murtomaa HT: Oral health among 35- to 44-year-old Iranians. Med Princ Pract 2007; 16:280-285.

27 Hessari H, Vehkalahti MM, Eghbal MJ, Samadzadeh H, Murtomaa HT: Oral health and treatment needs among 18-year-old Iranians. Med Princ Pract 2008;17:302-307.

28 Klock KS: Patients' perceptions of the decision-making process leading to extraction of permanent teeth in Norway. Community Dent Oral Epidemiol 1995;23:165-169.

29 Worthington H, Clarkson J, Davies R: Extraction of teeth over 5 years in regularly attending adults. Community Dent Oral Epidemiol 1999;27:187.

30 Pakshir HR: Dental education and dentistry system in Iran. Med Princ Pract 2003; 12(suppl 1):56-60. 